\title{
Monitoring Data Center Cyber dengan Camera Network Fiber Optik
}

\author{
Dimpo Sinaga \\ dnagas1@yahoo.com
}

\begin{abstract}
In dealing with free trade there will be complex problems in the business world. One of the complex problems is the need for extensive information that can be useful for both internal and external parties. Especially in the field of server data rack rental business, because this business requires a lot of capital so it needs a computerized security system. The problem faced today is to facilitate the process of leasing server data racks and based on these problems. Networking is a set of computers that are connected by cable or wireless to other computers in order to communicate with each other, exchange information, share files and printers. The advantages of networking can produce information that is useful for the interests of internal and external parties.
\end{abstract}

\section{PENDAHULUAN}

\section{A. Latar Belakang}

Didalam menghadapi perdagangan bebas maka akan muncul masalahmasalah yang komplek didalam dunia usaha. Salah satu masalah yang komplek itu adalah dibutuhkannya informasi yang luas yang dapat berguna bagi kepentingan pihak internal maupun pihak eksternal. Terutama di bidang usaha penyewaan rack data server, karena bidang usaha ini membutuhkan banyak modal sehingga perlu adanya system keamanan yang sudah terkomputerisasi. Masalah yang dihadapi saat ini adalah memudahkan proses penyewaan rack data server dan berdasarkan masalah tersebut.

Networking adalah sebuah himpunan komputer yang dihubungkan dengan kabel atau nirkabel dengan komputer lainnya agar dapat saling komunikasi, bertukar informasi, berbagi (shared) file dan printer. Kelebihan networking dapat menghasilkan informasi yang berguna bagi kepentingan pihak internal maupun eksternal perusahaan.

\section{B. Ruang Lingkup}

Maka ruang lingkup yang mencakup yaitu ruang Data Center Cyber dengan banyaknya metode pengamanan yang memiliki karakter berbeda-beda, maka dalam penulisan ini dibataskan masalah hanya sebatas mengimplementasikan camera network dengan menggunakan fiber optik pada ruang Data Center Cyber.

a. Memberikan keamanan dengan kemudahan dalam memonitoring proses data diterima dalam satu suatu ruang.

b. Monitoring real time pada ruang data center. 
c. Mengawasi serta memantau kinerja para engineer yang memantau kegiatan troubleshooting.

\section{Metode Penelitian}

Untuk mendapatkan data penunjang serta teori pelengkap dalam penyusunan skripsi ini maka membutuhkan data-data yang tepat dan baik, dalam mendapatkan hasil data-data yang diperlukan tersebut dengan menggunakan beberapa metode.

\section{Metode Studi Lapangan}

Studi lapangan dimaksudkan untuk memperoleh data yang menyangkut pelaksanaan suatu kegiatan dan juga untuk membuat gambaran mengenai situasi atau kejadian, sehingga metode ini bertujuan mengadakan akumulasi data dasar atau suatu metode penelitian lapangan yang meneliti suatu objek riset, suatu sistem ataupun suatu peristiwa pada masa lalu dan rencana yang akan datang. Hal ini dilakukan untuk mendapatkan gambaran secara sistematis, cermat dan akurat mengenai fakta yang ada.

Adapun cara yang ditempuh dengan menggunakan teknik penelitian ini adalah sebagai berikut :

\section{a. Observasi.}

Mengadakan pengamatan secara langsung dilapangan dengan mengamati proses kegiatan keamanan yang kemudian dianalisa suatu kesimpulan yang merupakan bahan yang diperlukan.

\section{b. Wawancara.}

Melakukan pengumpulan data dengan melakukan kegiatan tanya jawab secara langsung kepada pihakpihak yang terkait untuk memperoleh view yang berhubungan dengan ke- amanan dan permasalahan yang dihadapi.

\section{c. Studi Pustaka.}

Metode pengumpulan data dengan cara membaca buku-buku referensi yang erat dengan hubungannya dengan masalah yang diteliti.

\section{LANDASAN TEORI \\ ANALISA SISTEM JARINGAN KOMPUTER}

\section{A. Topologi dan Infrastruktur Jaringan Komputer.}

1. Topologi Jaringan Komputer.

Pada penggunaan saat ini, topologi jaringan yang digunakan adalah Topologi Star, karena topologi star sangat mudah untuk menambahkan perangkat dan ketika sedang melakukan maintenance sangat mudah untuk mendiagnosa suatu kesalahan pada jaringan.

\section{Infrastruktur Jaringan Komputer.}

Berikut adalah topologi jaringan yang digunakan.

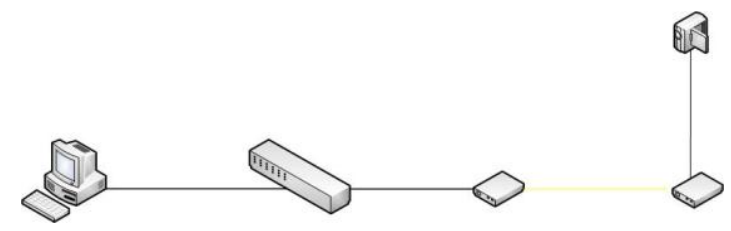

Gambar 3.2

Topologi Jaringan

Keterangan :

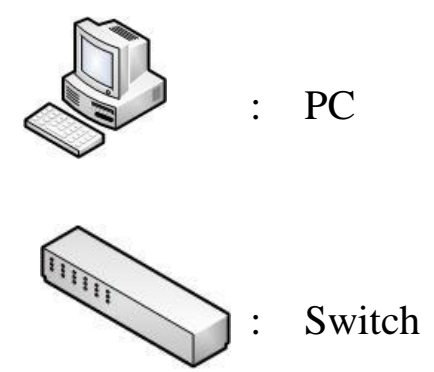




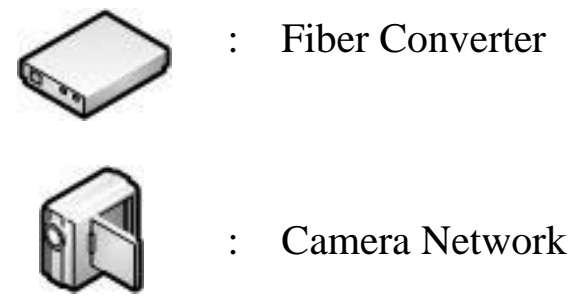

\section{Penjelasan :}

PC yang berada pada ruangan NOC akan monitoring selama $7 \times 24$ jam tanpa henti namun tidak selamanya akan lakukan recording, recording akan dilakukan ketika ada yang sedang melakukan maintenance di ruang Data Center.

PC yang terhubung dari ruangan NOC akan tersambung ke perangkat Switch yang berada di ruang Server dengan menggunakan kabel Lan RJ 45 Cat.5 kemudian dari perangkat Switch akan di teruskan ke Fiber Converter dari Lan ke kabel Fiber Optik Single Mode yang disambungkan ke Fiber Converter yang berada di ruangan Data Center berdasarkan lantai gedung yang akan digunakan untuk Camera Network.

Dari Fiber Converter tsb akan diubah kembali dari kabel Fiber Optik Single Mode ke kabel Lan RJ 45 Cat5 yang akan diteruskan ke Camera Network.

\section{Cara Pengaksesan Data.}

Cara pengaksesan data dengan menggunakan software dari perangkat Camera Network yaitu Air Cam Vision dan Air Cam NVR.

Berikut adalah gambar cara pengaksesan data :

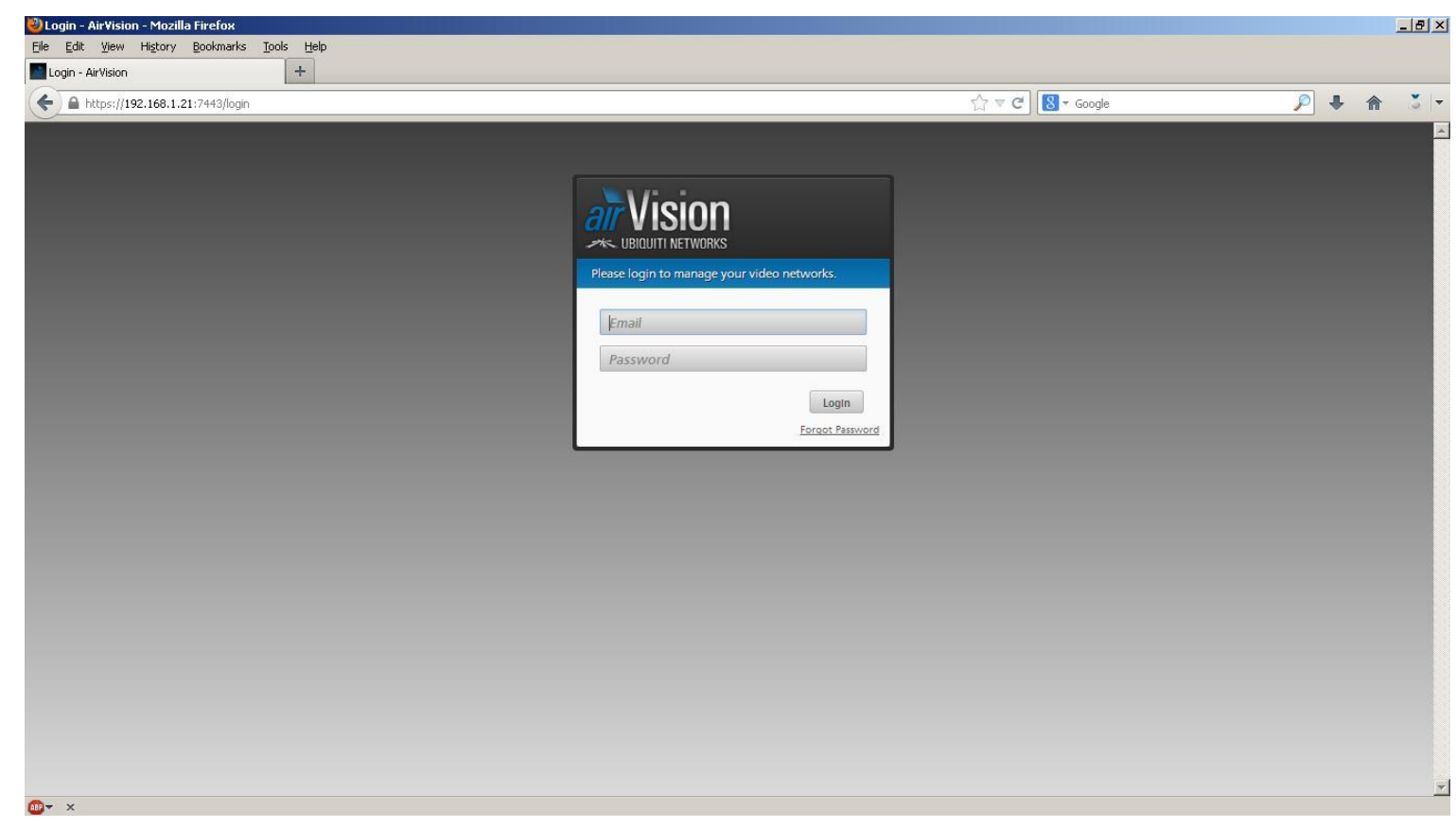

Gambar 3.3

Login Monitoring Camera Network 


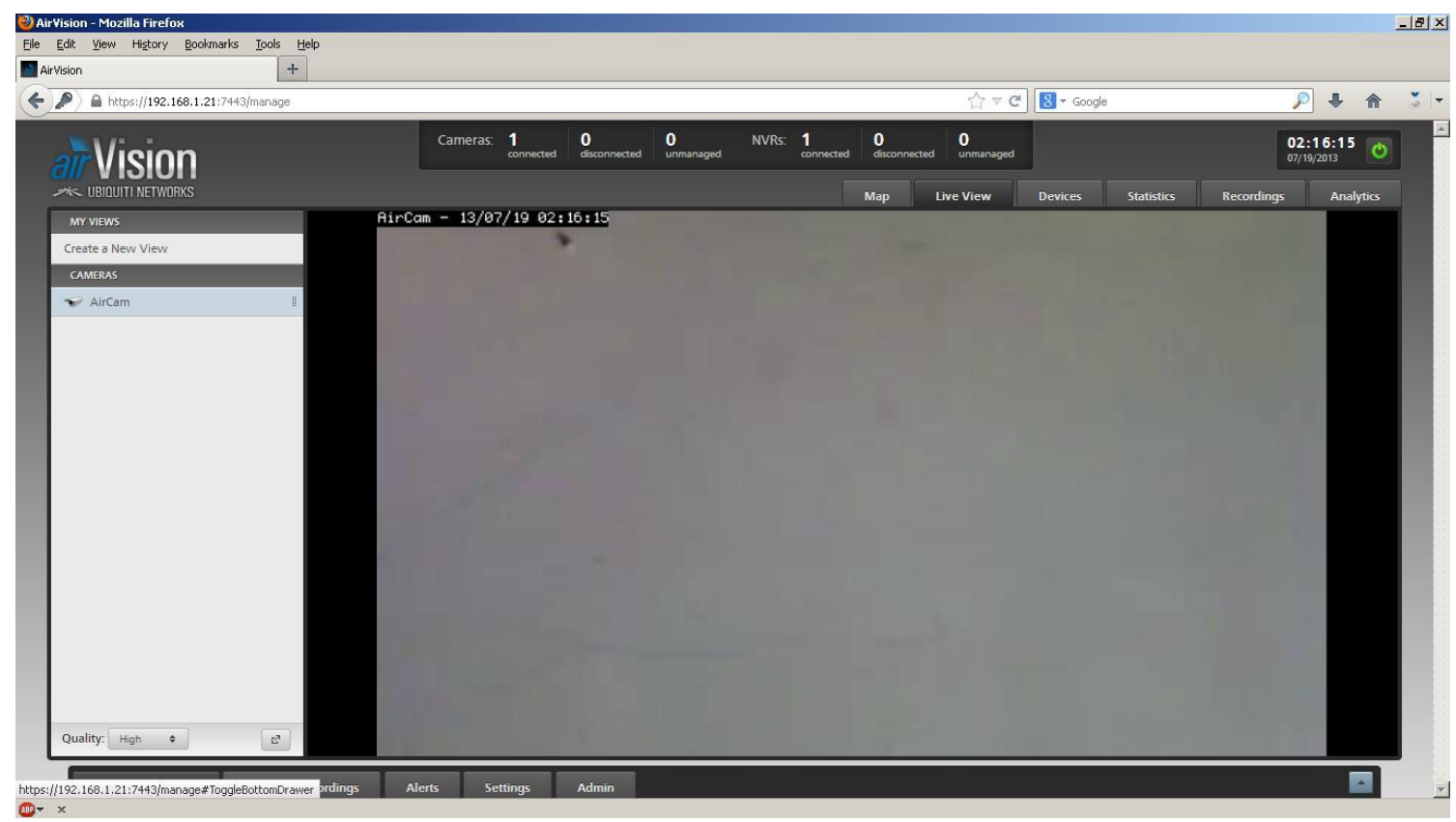

Gambar 3.4

Monitoring Camera Network

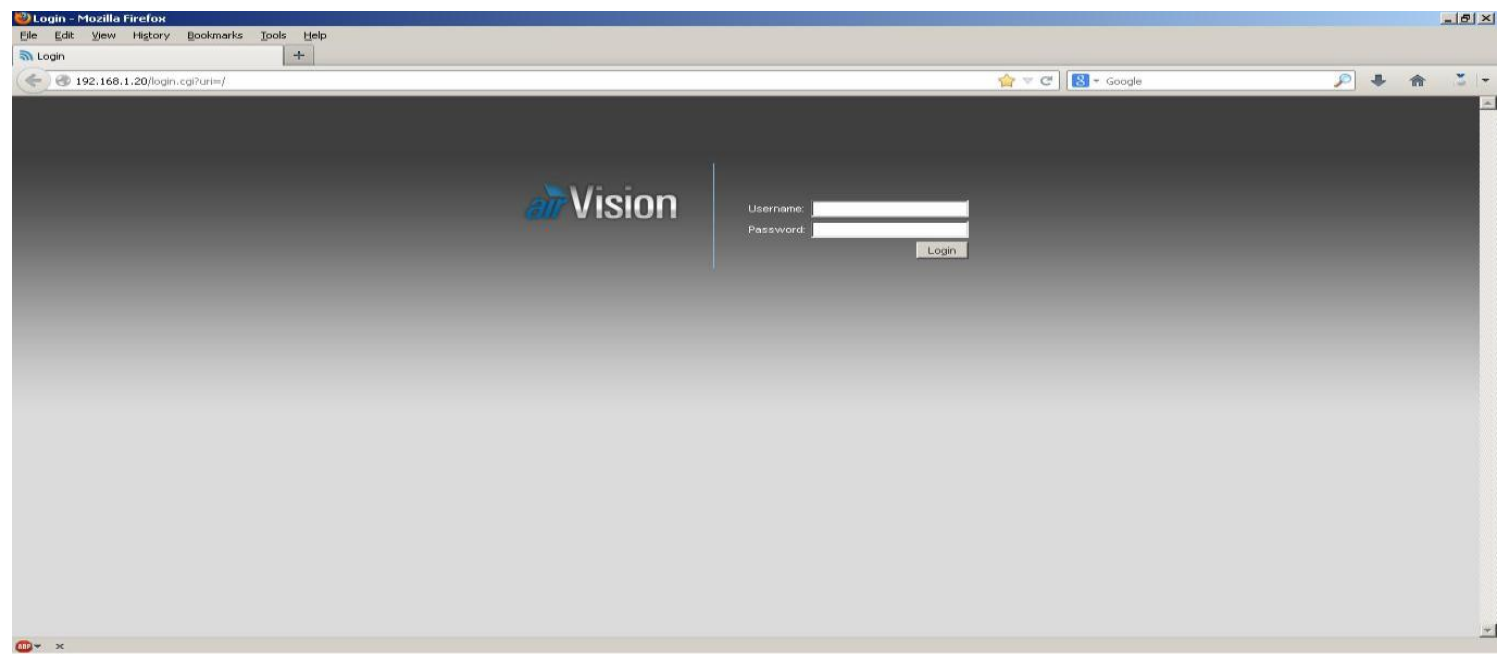

Gambar 3.5

Login Konfigurasi Camera Network 


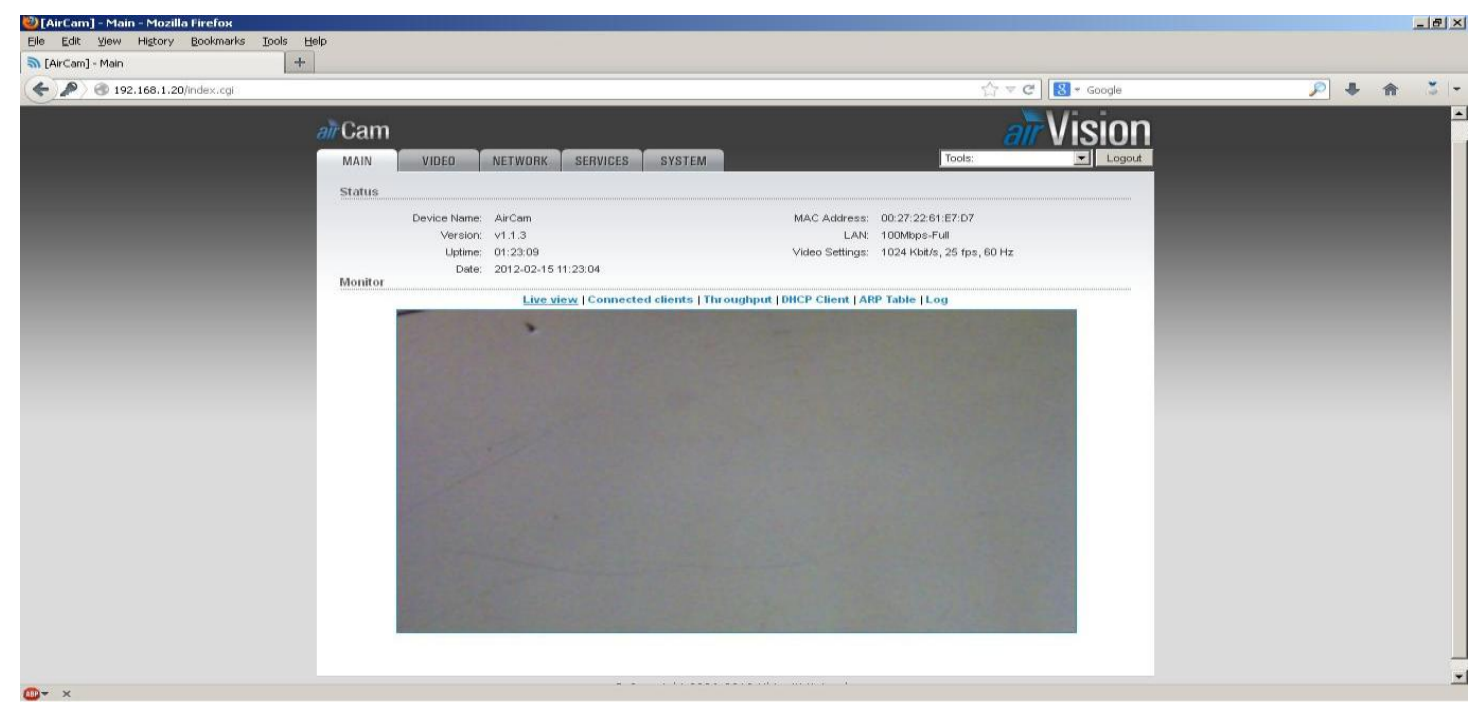

\section{Gambar 3.6}

Status Konfigurasi Camera Network

\section{Kecepatan Akses Data.}

Pada penelitian ini untuk melakukan pengetesan kecepatan akses data dengan menggunakan software Visual Ping, dimana software ini berfungsi untuk mengetes kecepatan akses data dengan cara menempatkan ip yang akan dituju.

Untuk penelitian ini penggunaan ip pada laptop dan camera network adalah sebagai berikut :

\section{Ip Laptop 192.168.1.21}

Ip Camera Network 192.168.1.20

Setelah dilakukan pengetesan kecepatan akses data dengan pengiriman paket data sebanyak 1000, maka hasil yang didapat dari pengetesan adalah :

1. Kecepatan akses data rata-rata adalah $3 \mathrm{~ms}$.

2. Kecepatan akses data cepat adalah $2 \mathrm{~ms}$.

3. Kecepatan akses data lambat adalah $11 \mathrm{~ms}$.

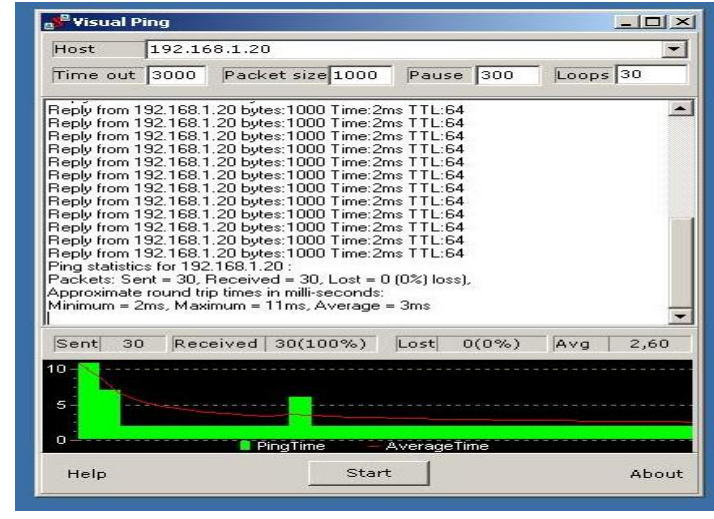

Gambar 3.7

Hasil Kecepatan Akses Data

\section{B. Analisa Permasalahan Sistem Jaringan Komputer.}

Pada penelitian yang dilakukan di perusahaan ini ternyata masih terdapat masalaha dilihat dari masih banyaknya celah-celah yang dapat dimasuki oleh para hacker.

1. Masih adanya celah masuk hacker ke dalam sistem jaringan.

2. Kurangnya pengetahuan staf mengenai keamanan jaringan. 
3. Diperlukan adanya backup link.

\section{SISTEM JARINGAN KOMPU- TER USULAN \\ Sistem Keamanan Usulan.}

1. Sistem Keamanan Jaringan Komputer Usulan.

Sistem keamanan jaringan komputer yang diusulkan untuk server dan komputer untuk terminal / client adalah :

\section{a. Merubah Nomor Port.}

Adalah sebuah metode sederhana dengan merubah nomor port default HTTP, FTP, TELNET dan HTTPS.

\section{b. Enkripsi Level.}

Merupakan sejumlah metode yang ada untuk otentikasi login aman dan sesi enkripsi telnet dan relogin yang merupakan contoh dari enkripsi pada tingkat tertinggi dari lapisan aplikasi.

\section{Sistem Keamanan Data Usulan.}

Sistem keamanan data untuk di server dan komputer untuk terminal / client adalah :

\section{Hak Akses.}

Adalah sebuah cara untuk memberikan hak akses seseorang untuk masuk kedalam data dan hak akses ini akan diberikan oleh seorang Administrator kepada user untuk dipergunakan sesuai dengan hak akses-nya dengan melakukan login.

\section{Metode Pengujian.}

Berikut adalah langkah-langkah untuk melakukan pengujian :

1. Pasang perangkat dari camera network ke media converter melalui fiber optik.

2. Kemudian dari media converter disambungkan ke switch melalui kabel LAN rj-45.
3. Dari switch disambungkan ke laptop / pc melalui kabel LAN rj45.

4. Seting ip static pada laptop yaitu 192.168.1.21

5. Kemudian seting juga pada camera network dengan ip static yaitu 192.168.1.20

\section{Analisa Biaya.}

Berikut adalah analisa biaya monitoring Camera Network menggunakan Fiber Optik :

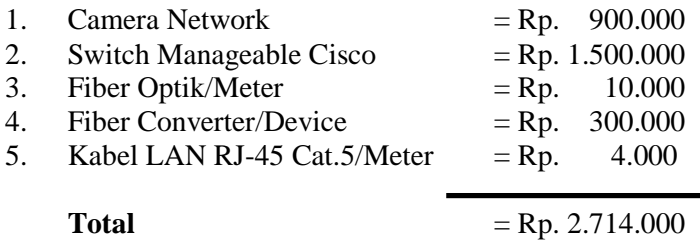

Untuk monitoring camera network menggunakan fiber optic tidak diperlukan adanya mesin DVR yang hanya mempunyai 4 port dengan keterbatasannya, namun dengan camera network tidak ada batasan dalam perangkat recording karena sudah ada software NVR yang dapat menampung semua camera network yang terhubung dengannya.

\section{PENUTUP}

\section{A. Kesimpulan.}

Saat ini semua sistem keamanan masih bersifat manual yaitu masih menggunakan log book dan personel staf yang datang untuk melakukan pengecekan ketika sedang ada yang maintenance.

Dengan adanya camera network dapat mempermudahkan kinerja staf hanya cukup monitoring dari ruang NOC.

Staff NOC akan melakukan recording begitu ada yang melakukan maintenance serta akan melakukan pengece- 
kan fisik setelah maintenance selesai dilakukan.

\section{DAFTAR PUSTAKA}

Mulyanto, Agus. Model Jaringan

Komputer dan Topologi. Jakarta.

Informatika Utama. 2009

Irawan, Budhi. Jaringan Komputer.

Yogyakarta. Graha Ilmu. 2008

Susilo. Internetworking. Jakarta.

Gramedia Pustaka Utama. 2007.

Mawardi, Imam. Network serta Metode

Implementasinya. Jakarta.

Gramedia Pustaka Utama. 2009.
Sofana, Iwan. Membangun Jaringan

Komputer. Bandung. Informatika. 2008.

Harry, James. Local Area Network A

User's Guide for Business

Professionals. London. Scott and

Foresman Company. 2009

Nugroho. Pengertian Internet dan

Intranet. Bandung. Informatika.

2008

Kurniawan, Wiharsono. Konfigurasi

Jaringan Komputer. Yogyakarta. Graha Ilmu. 2008 